\title{
Constructing end-to-end models using ECOPATH data
}

John H. Steele Woods Hole Oceanogr. Instn, Woods Hole MA 02543, USA

James J. Ruzicka Oregon State U., 2030 SE Marine Science Dr., Newport OR 97365

Corresponding author: jsteele@whoi.edu

\begin{abstract}
The wide availability of ECOPATH data sets provides a valuable resource for the comparative analysis of marine ecosystems. We show how to derive a bottom-up transform from the topdown ECOPATH; couple this to a simple NPZD web with physical forcing; and use the end-toend model (E2E) for scenario construction. This steady state format also provides a framework and initial conditions for different dynamic simulations. This model can be applied to shelf ecosystems with a wide range of physical forcing, coupled benthic/pelagic food webs, and nutrient recycling.

We illustrate the general application and the specific problems by transforming an ECOPATH model for the Northern Californian Current (NCC). We adapt results on the upwelling regime to provide estimates of physical fluxes and use these to show the consequences of different upwelling rates combined with variable retention mechanism for plankton, for the productivity of fish and other top predators; and for the resilience of the ecosystem. Finally we show how the effects of inter-annual to decadal variations in upwelling on fishery yields can be studied using dynamic simulations with different prey-predator relations.

The general conclusion is that the nature of the physical regimes for shelf ecosystems cannot be ignored in comparing end-to-end representations of these food webs.
\end{abstract}

Key words: marine ecosystems, end-to-end, California Current, scenarios

\section{Introduction}

The ECOPATH representation of marine food webs (Christensen and Walters, 2004) has proven very useful in illuminating the consequences of harvesting commercial fish stocks on the rest of the fish community and on intermediate trophic levels. It has been less helpful in developing end-to-end models that include the physical and biogeochemical processes at the bottom of the food web. The main reason is that ECOPATH has a linear top-down formulation with the input being fish catches and the output as rates of production by phytoplankton and detritus needed to fuel these catches. This approach utilizes the large data bases for the diets of fish but has some drawbacks. It does not include nutrient recycling in the microbial food web. It does not account for the physical exports of plankton that are a concomitant of the physical input of nutrient rich waters, and a dominant feature of shelf ecosystems. Further, since the top-down information flow is opposite to the bottom-up energy flux, the linear system is inherently unstable (Steele, 2009) and so ECOPATH requires significant non-linear restructuring for its use in dynamic simulation, ECOSIM (Walters et al., 1997). A bottom-up simulation is inherently stable allowing direct study of the effects of perturbation under both linear and non-linear assumptions (Steele, 2009). 
Mathematically it is simple to transform a top-down linear solution (ECOPATH) into a bottomup model (Steele, 2009) here called ECOTRAN. In principle it is then easier to use a steady state description of annual NPZD fluxes as input to this model. However this lower food web is much more dependent on the physical processes that drive nutrient inputs and physical exports of $\mathrm{P}, \mathrm{Z}$ and $\mathrm{D}$. There is a great spatial and temporal variety in the physical environments of continental shelf ecosystems that are the focus of present interest in the effects of climatic change and overfishing. Essential lateral interactions, Fig. 1, are required for models on the shelf, compared with the typically vertical model systems used for the open ocean. Shelf systems are dominated by their physical exchange rates that range from semi-enclosed seas such as the North Sea where river input and regeneration of nutrients from the benthos are important; through offshore fishing grounds such as Georges Bank; to eastern boundary upwelling regions where nutrient fluxes from deep water drive the system. Further, seasonal variations in nutrient input and phytoplankton production play a major role in determining energy fluxes to higher trophic levels. These space/time components need to be considered when estimating the single annual rates for energy input to the upper level components of each ecosystem.

Continental shelf systems pose much more difficult research problems than open ocean systems because the sea bed topography and benthos must be considered integral parts of the physical dynamics, the biogeochemical cycling and food web processes leading to fish capture. Yet recent reviews (Travers et al, 2007; Rose et al, 2010; Moloney et al, 2010) focus on the planktonic components. Rose et al (2010) relegate the issues raised by benthic-pelagic coupling to "further work" and this is typical of many other studies that consider only pelagic or open ocean ecosystems. But it is regions on continental shelves that generate the most pressing management issues and attract most public attention. For these reasons we have chosen to investigate all components of exploited shelf ecosystems recognizing that inclusion of microbial processing of detritus in the water column and the sea bed, and nutrient recycling through plankton and benthos, will complicate small scale physical biological coupling.

The approach developed here permits incorporation of parameters representing spatial aspects such as lateral fluxes and vertical migration. In a comparable Georges Bank study (Steele et al, 2007) the lower food web fluxes were determined for three regions on the Bank and for three seasons. More complex models such as ERSEM (Baretta et al, 1995) or ATLANTIS (Fulton and Smith, 2004) use regional oceanographic models. It is not clear how far variable output from these physical simulations is incorporated directly into the food web fluxes or, especially, in fish production. Applications of ERSEM have been mainly at lower and intermediate trophic levels, rather than for fish production (e.g., Petihakis et al, 2007). ATLANTIS is intended to provide management strategy evaluations (MSE's) of particular regions rather than comparison of diverse shelf ecosystems

Part of the success of ECOPATH results from the general applicability of the computer program. By ignoring the effects of different physical processes it can be used in the analysis of the upper levels of any shelf ecosystem. For end-to-end models that include the microbial food web, the effects of these physical factors must be addressed. Thus the incorporation of NPZD processes can require individual treatment for each ecosystem. The wide availability of ECOPATH data sets, however, provides a valuable resource as part of the comparative analysis of marine ecosystems. We illustrate the general application and the specific problems by transforming an 
ECOPATH model for the Northern Californian Current (NCC) based on Ruzicka et al. (2007). We adapt results on the upwelling system to provide data for an annual estimate of physical fluxes and use these to show the consequences of variable upwelling. Finally we show how dynamic simulation of inter-annual to decadal variations can be studied (Steele, 2009).

Section 2 describes the theoretical basis and general procedures for constructing an E2E food web using ECOPATH data. Section 3 illustrates these methods by application to the Northern California Current and displays some of the possible outputs. Section 4 discusses the main conclusions from theory and application. The MATLAB computer programs (ECOTRAN) used in this paper are available from jim.ruzicka@noaa.gov.

\section{ECOTRAN: End-to-End food web model constructed using ECOPATH data}

\subsection{Theory}

A general form for a prey-predator food web (Steele, 2009) is

$$
d B_{p} / d t=e_{p}\left(\operatorname{sum}\left(B_{b} \text { consumed by } B_{p}\right)+G_{p}\right)-\operatorname{sum}\left(B_{p} \text { consumed by } B_{c}\right)-L_{p}
$$

where $B_{p}=$ biomass of "functional group" $p$;

$G_{p}=$ gains from external sources, e.g., nutrient input to phytoplankton, $\left(G_{p} \geq 0\right)$;

$L_{p}=$ losses from the system $\left(L_{p} \geq 0\right)$;

$e_{p}=$ production efficiency $=$ production/consumption $\left(P_{p} / C_{p}\right)$, (const. for each $\left.p\right)$.

If, for simplicity, we assume that the fraction of production lost to mortality by senility or illness is small compared to predation, then $e_{p}=$ transfer efficiency of consumption across trophic levels.

The units of biomass can be energy, live weight, particulate organic carbon or a nutrient such as nitrogen. In the last case, “consumption” can include the uptake of nutrients input into the system by autotrophs or the flow of recycled nutrients from heterotrophs to autotrophs.

Given three trophic levels, $c$ feeding on $p$ and $p$ feeding on $b$, let $Q_{p c}=$ the rate at which $B_{p}$ is consumed by $B_{c}$, then,

$$
d B_{p} / d t=e_{p}\left(\sum_{b} Q_{b p}+G_{p}\right)-\sum_{c} Q_{p c}-L_{p}
$$

If we take $P_{p} / B_{p}$ (= $r_{p}=$ turnover rate) as constant for each group $p$, then production $P_{p}$, total consumption $C_{p}$, or biomass $B_{p}$ can be used as state variables. For an examination of steady state webs we use $C_{p}$ or $P_{p}$.

In general, $Q_{p c}=f\left(C_{p}, C_{c}\right)$ or $f\left(P_{p}, P_{c}\right)$, but non-linear formats do not generally permit steady state numerical solutions for large webs. A simplification is to linearize the system permitting matrix solutions for the steady state. There are two options:
(A) $\quad Q_{p c}=a_{c p} P_{p} \quad a_{c p} \geq 0$
(bottom-up)
(B)
$Q_{p c}=b_{p c} C_{c} \quad b_{p c} \geq 0$
(top-down) 
where $a_{c p}=$ the production matrix (or "predator matrix") defining the fraction of total production by each producer $p$ consumed by each consumer $c$;

$b_{p c}=$ the diet matrix defining the fractional contribution of each prey type $p$ in the diet of each predator $c$.

Note that (A) follows the expected direction of energy flux, with the production of prey determining the intake by predators; whereas for (B) the consumption by the predator determines the output production of the prey. Thus (A) is a "bottom-up" solution, and (B) is a "top-down" solution. Note also that

$$
\sum_{c} a_{c p}=1 \quad \text { and } \quad \sum_{p} b_{p c}=1
$$

(A) The "bottom-up" option has been used in many marine food webs (e.g. Steele, 1974; Sissenwine et al, 1984). At steady state $d B_{p} / d t=0$; therefore,

$$
e_{p}\left(\sum_{b} a_{p b} P_{b}+G_{p}\right)-\sum_{c} a_{c p} P_{p}-L_{p}=0
$$

where $L_{p}=f_{p} P_{p}$, and

$f_{p}=$ fractional loss of $P_{p}$ from the system (e.g., by fishing or physical export).

Rearrangement of eq. 3 gives,

$$
P_{p}=e_{p}\left(\sum_{b} a_{p b} P_{b}+G_{p}\right)-f_{p} P_{p}
$$

Traditionally, the upper closure of the numerical system is obtained by assuming the complete removal of take by fishery $p=n$ from the system $\left(a_{n c}=0, f_{n}=1\right)$ and no input to the fishery from outside the system $\left(G_{n}=0\right)$.

The quantitatively most important "losses" from shelf systems are by physical transport out of the system. This transport can be substantial for lower trophic levels in cases such as upwelling ecosystems, and needs to be incorporated in the calculations.

(B) The alternative "top-down” approach used in ECOPATH (Christensen and Pauly, 1993)

$$
Q_{p c}=b_{p c} C_{c}
$$

has the upper trophic level determine the rate for each pair $C_{p}, C_{c}$. Then,

$$
e_{p} \sum_{b} b_{b p} C_{p}-\sum_{c} b_{p c} C_{c}+e_{p} G_{p}-L_{p}=0
$$

where $\sum_{b} b_{b p} C_{p}=1 \cdot C_{p}$ is the total consumption by $p$ on all its prey groups $b$, and $\sum_{c} b_{p c} C_{c}$ is the total predation on $p$ by all predator groups $c$. Therefore, 


$$
P_{p}=e_{p} C_{p}=\sum_{c} b_{p c} C_{c}-e_{p} G_{p}+L_{p}
$$

Traditionally, the top-down, steady-state solution (eq. 6) is obtained by assuming transfer efficiencies $e_{p}$, the diet matrix $b_{p c}$, fishery yields $Y_{p}=e_{p} G_{p}$, and losses $L_{p}$ are known, allowing calculation of the total consumption $C_{p}$ of each group. Fisheries yields act, formally, as independent inputs. Terms such as primary production and detritus production are, formally, outputs. As such they will be linearly dependent on the inputs from the upper trophic levels. Thus information about the system flows down the food web from the input by fisheries and top trophic level predators.

ECOPATH, however, takes $b_{p c}, P_{p}, C_{p}, B_{p}$, and $Y_{p}$ as knowns from data. It assumes that transfer efficiencies are not known by introducing unknowns $E E_{p}$ and expressing transfer efficiency as $E E_{p}\left(P_{p} / C_{p}\right)$. Introducing these into (eq. 6), we can obtain the ECOPATH format:

$$
\left(P_{p} / B_{p}\right) \cdot B_{p} \cdot E E_{p}=\sum_{c} B_{c}\left(C_{c} / B_{c}\right) b_{p c}+Y_{p}+L_{p}
$$

The top-down solutions for the $E E_{p}$ are often adjusted during "model balancing” to remove inconsistencies in the solution where $E E_{p}>1$ (see Christensen and Pauly (1993) for details). Physical loss terms, $L_{p}=k_{p} B_{p}$, are not usually part of ECOPATH.

\subsubsection{Bottom-up transforms of top-down solutions}

The bottom-up and top-down formulations (A) and (B) are related by the alternative forms for each trophic link from producer $p$ to consumer $c$,

$$
a_{c p} P_{p}=b_{p c} C_{c}
$$

and by $P_{p}=\sum_{c} b_{p c} C_{c}-e_{p} G_{p}+L_{p} \quad(p \neq c)$.

Then,

$$
a_{c p}=\frac{b_{p c} C_{c}}{\sum_{c} b_{p c} C_{c}-e_{p} G_{p}+L_{p}} .
$$

The $a_{i j}$ cannot be estimated from the individual $b_{j i}$ but are only obtained from the complete topdown solution for the component consumptions $C_{j}$. Given a top-down solution, as in ECOPATH, it is, in principle, simple to derive the "predator" matrix $a_{i j}$ required for a bottom-up representation of the same web. In ECOPATH, physical exports are not included since they are only significant for the plankton. So in practice $L_{p}=0$. The external input terms, $G_{p}$, go from the top to the bottom of the web and need to treated separately. So, in practice, the transform is given by 


$$
a_{c p}=\frac{b_{p c} C_{c}}{\sum_{c} b_{p c} C_{c}}
$$

There is a particular problem with the diagonal terms of the diet matrix $b_{p p}$ that represent trophic cannibalism. Cannibalism is recycled energy flow that does not contribute to group production but does reduce overall group transfer efficiency between trophic levels. These terms are quite common in ECOPATH diet matrices, especially when there has been some aggregation into functional groups. In a straight transpose, $a_{p p}=b_{p p} / e_{p}$. Although $b_{p p}$ may be small, $a_{p p}$ can be large. The fraction of total production by group $p$ available to predators is $1-b_{p p} / e_{p}$. For example, $10 \%$ cannibalism for a group with $20 \%$ transfer efficiency between trophic levels means that the production available for predators will be $50 \%$ of that without cannibalism. To eliminate the diagonal terms we take $b_{p p}=0$, normalize the columns $b_{c p}$ to sum to unity, and reduce the transfer efficiency as $e_{p}-b_{p p}$.

\subsection{Constructing an End-to-End food web from a bottom-up transform}

The top-down ECOPATH method makes full use of the extensive fish data on $P / B, C / B$ ratios and diets. The bottom-up approach uses literature syntheses of experiments on plankton and benthos to derive general transfer efficiencies $e_{p}$ rather than attempt estimates from limited data

for each food web. The choice between methods may be a matter of emphasis based on available data for upper trophic levels (fish) versus lower trophic levels (plankton).

Given the bottom-up transform derived from the top-down (ECOPATH) solution (via eq. 9), the inputs to the system are usually phytoplankton and detritus production, Fig. 2A. To convert the bottom-up transform to an end-to-end representation requires the addition of a microbial food web that quantifies (i) external nutrient fluxes as input for uptake by autotrophs, (ii) nutrient processing via plankton and benthos feces and excretion, (iii) nutrient recycling via the microbial oxidation of detritus production, (iv) losses from the system by physical export and denitrification. An E2E web must also take account of (v) the smaller space and time scales that are important for the microbial food web. In general, the calculation of annual averages for these lower trophic levels over the whole ecosystem may require initial subdivision into smaller spatial and shorter temporal components to capture the topography and seasonal cycling of the lower planktonic web (e.g., Steele et al., 2007); or construction of NPZD models that are then used for annual averages (Aydin et al., 2007). Choice of method will depend on the nature of the system and the data available.

\section{$\underline{2.21 \text { Physical Fluxes }}$}

An accurate model of energy flow through a shelf ecosystem must account for both new production supported by influx of nutrient-rich water and production lost from the system via physical transport mechanisms, Fig. 1. For large semi-enclosed systems such as the North Sea, input/output fluxes may be less significant than for smaller offshore regions such as Georges Bank (Heath and Beare, 2009; Steele et al., 2007). Overall, varying flux rates can be expected to 
be a defining feature in the comparison of shelf ecosystems. These fluxes are especially critical for coastal upwelling systems, like the Northern California Current (NCC) with a narrow continental shelf (Ruzicka et al., 2007).

\section{$\underline{2.22 \text { Nutrient processing }}$}

Lower trophic level grazers are the greatest contributors to recycling and the pathways for feces and NH4 excretion are critical. . Each of the four zooplankters (micro-, herbivorous, carnivorous zooplankton and jellies) can have different "behavior". We assume that microzooplankton feces contribute to pelagic detritus whereas for macro- and carnivorous plankton, fecal material sinks rapidly to the benthic food web. Correspondingly NH4 excretion for microzooplankton contributes to the euphotic zone but vertical migration of the larger plankton can result in some fraction of NH4 excretion going to the lower layers.

The fecal contribution to the benthos can be $30 \%$ or more of primary production. This is consumed by microbial and invertebrate components of this food web that, in turn recycle nutrients to the lower layers of the water column. The time delay in these multiple steps is important in relation to the return of nutrients to the upper layers for re-use in primary production. Circumstantial evidence (Steele and Collie, 2005; Ruardij and Raaphorst, 1995) indicates time scales of 50-150 days.

\subsection{Nutrient recycling}

Unlike open ocean systems where the processing of fecal material is assumed to occur in a separate system, the benthic and pelagic components of shelf ecosystems can be closely coupled. Given the wide range of residence times for water within shelf ecosystems, the significance of this coupling can vary greatly; from reliance on external input in coastal upwelling to dependence on recycled nutrients in semi-enclosed systems with long residence times. For the latter there is also the question of unknown losses of available nitrogen by denitrification (Seitzinger and Giblin, 1996). All these factors make the rate of return and fraction returned to the upper layer a critical, but little known, component in the overall productivity; comparable to the f-ratio for open ocean systems but involving more complicated biogeochemical processes (Eppley and Peterson, 1979).

\subsection{Plankton Export}

Systems with high flux rates of nutrients to fuel primary production can have a problem with wash out of plankton. For some systems, particularly coastal upwelling regimes, the residence time of water in the upper, productive, layer can be 10-30 days. For larger organisms, the potential rate of loss can equal or be greater than the growth rate, making the populations unsustainable. It is generally accepted that diel and ontogenetic vertical migration minimize the time these populations spend in the surface layer and reduce (or reverse) offshore transport (Lamb and Peterson, 2005, Batchelder et al., 2002, Peterson, 1998; Carr et al, 2008). But increased time at depth may also decrease recycling of NH4 to the upper layer. Obviously the resultant net flux rates are very dependent on the exact time and depth range of this migration. The detailed mechanisms for such interactive features cannot be included in a simplified annual budget, and there are inadequate data to estimate these rates. In NPZD models these losses are 
usually regarded as closure terms. Here they are critical to determination of the inputs to higher trophic levels. It will be necessary to regard this loss rate as an unknown and examine the consequences of a range of values.

\subsection{Space and Time Scales}

Energy flow in the upper levels of shelf food webs is normally expressed in terms of annual rates and at the spatial scales of the major fish populations. These scales are much larger than the dimensions associated with NPZD models - days/weeks and tens of kilometers. Although some models (e.g. Fulton et al, 2004) use intermediate scales to couple lower and upper trophic levels, full coupling across trophic levels require fine scales with resultant very large demands on computers and their programmers (Rose et al, 2010). these models confine their subject matter to pelagic systems and, for the present, ignore benthic components (Rose et al, 2010) for obvious reasons. We wish to examine a wide range of shelf ecosystems (Murawski et al, 2009) and so confine the models to intermediate levels of complexity (Hannah et al, 2009).

This requires simplification of the physical system in a way that permits integration across space and time to provide annual estimates of production by plankton for the whole ecosystem. One method uses tidal fronts (Simpson and Hunter, 1974) and their range of displacement to define different vertical mixing regimes for different seasons (e.g. Bisagni, 2003 for Georges Bank; Heath and Beare, 2009 for the North Sea). Alternative approaches appear necessary for upwelling systems (see later text). The last step is to use the annual fluxes of NPZD derived from these calculations to drive a restructured food web, Fig. 2B. The input rates for primary production and detritus in Fig. 2B will be different from the estimated outputs obtained from ECOPATH. Estimates of production will differ from the ECOPATH values. Because of this and because different assumptions are made about trophic efficiencies, the two solution are quasi independent.

\section{Scenarios and Dynamic simulations}

The steady state solution, ECOTRAN obtained by these calculations is, formally, a description of the system in terms of quantities of energy/carbon/nutrients $\left(a_{p c} . P_{p}=b_{c p} . C_{c}\right)$ exchanged annually between functionally defined food web components. The great benefit is that this solution provides a base line for constructing scenarios; or as an initial condition for dynamic simulations. It does not determine cause and effect. This enters when we use one or other format - $a_{p c}$ or $b_{c p}$ to manipulate the system. The former is preferable because it conforms to the general direction of energy flow. Scenarios can be constructed to illuminate the food web effects resulting from changes in primary production, benthic/pelagic ratios, jellies, and abundance of juvenile or adult fish (Collie et al, 2009).

Because ECOTRAN is donor controlled, it is straightforward to convert the steady state solution to a dynamic simulation (Steele, 2009) where the state variables are the production rates, $X_{p}(t)$ with

Then

$$
X_{p}(t)=P_{p} \text { at } \quad t=0
$$

$$
d X_{p} / d t=r_{p}\left[e_{p} \sum_{b \neq p} a_{p b} X_{b}-\sum_{c} a_{c p} X_{p}+e_{p} G_{p}-f_{p} X_{p}\right], \quad e_{p} \leq 1 ; \quad \sum a_{c p}=1
$$


The only added data required are the growth rates of the components $(r=P / B)$.

Such open linear dynamic systems with independent external input are inherently stable, and are ergodic in the sense that they "forget" their initial conditions. A closed system, for example when nutrients are completely recycled, is determined by its initial conditions. Shelf ecosystems with both external nutrient input and extensive recycling will be ergodic but the temporal response of the system to perturbation will be closely linked to the relative roles of external input and recycling. Semi-enclosed systems such as the North Sea will be dominated by recycling, whereas upwelling systems are extremely open. We consider the latter case for the NCC.

These linear models can be regarded as the zero order form for comparison with non-linear systems. As one formulation, we can assume that $Q_{p b}=f\left(X_{p}, X_{b}\right)$ with the constraint that

$$
Q_{p b}(t)=a_{p b} P_{b} \quad \text { at } t=0
$$

For example,

$$
Q_{p c}\left(X_{p}, X_{c}\right)=(n+1) a_{p c} X_{p} X_{c} /\left(n P_{c}+X_{c}\right), \quad X_{i}=P_{i} \text { at } t=0 \text {, for all } i
$$

gives different degrees of consumer $\left(X_{c}\right)$ density limitation with variable $n$. This is essentially the condition used in ECOSIM where $n$ corresponds to "vulnerability" (Christensen and Walters, 2004; Steele, 2009). We can introduce other non-linear functions for a range of computer simulations.

\section{$2.4 \underline{\text { Units }}$}

The units used for data from the upper and lower parts of the food web vary considerably. In the system used here, where nutrient recycling can occur at all trophic levels, nitrogen is the operational unit. NPZD models use concentrations given as $\mathrm{mm} \mathrm{N} . \mathrm{m}^{-3}$. However, for fish and other upper level components, the usual unit is biomass (or wet weight). $\mathrm{m}^{-2}$. Carbon is an alternative unit for both systems and will be used here. As scaling factors we use the Redfield ratio (6.625 mmole $\mathrm{C}$ mmole $\mathrm{N}^{-1}$ and the estimated carbon content of fish on Georges Bank (8.8 mg live weight $\mathrm{mg} \mathrm{C}^{-1}$ ) (Steele, 2007).

\section{ECOTRAN application: the Northern California Current}

We apply the general approach described in the previous sections to the NCC ecosystem by first constructing the ECOTRAN food web and comparing its output with the ECOPATH values. We demonstrate the effects of varying the physical forcing and the "unknown" residence times of the larger plankton on fish production. Then we construct scenarios to show the effects of changes in the internal food web structure. Finally we develop linear and non-linear dynamic simulations of decadal patterns in output at different trophic levels

\subsection{ECOTRAN: Bottom-up transform and nutrient cycling}

To illustrate the steps involved in the construction of an end-to-end model system from a topdown solution, we use an ECOPATH model of Northern California Current, NCC (Ruzicka et al., 2007). Following the methods described in the previous sections: 
(i) the ECOPATH diet matrix and consumption data (Ruzicka et al., 2007) were aggregated to the components given in Fig. 2A: and trophic cannibalism terms were removed

(ii) the bottom-up transformation was calculated using equ.(9) giving three inputs phytoplankton, benthic detritus, and pelagic detritus production), Fig. 2A.

(iii) The microbial food web with nutrient recycling was added, Fig. 2B. The system now has input of NO3 as the external driver; and the outputs are to fisheries and top predators.

(iv)Lower trophic level grazers are the greatest contributors to recycling within the upper water column. For each of the four zooplankters (micro-, herbivorous, carnivorous zooplankton and jellies), we assume that 20 - 30\% of intake goes to production (growth) and the remainder is split between $\mathrm{NH}_{4}{ }^{+}$and feces (Table 1). We assume that $50 \%$ of excretion by larger zooplankters is removed from euphotic zone due to vertical migration. Feces go to either pelagic or benthic detritus on the assumption that micro-zooplankton feces sink slowly whereas the others sink rapidly.

(v) The results of these manipulations for the NCC is given in the production matrix (Table 4) describing the flow of production of each group $p$ to each consumer $c$, to feces, or to nutrient recycling via excretion. To calculate production we use values of transfer efficiency, $e_{p}$, derived from the literature (see Steele et al, 2007), Table 2.

Comparisons of the ECOPATH and ECOTRAN production values in Table 2 show the consequences for the main trophic components (excluding top predators) of the addition of the microbial web, recycling and different methods of estimating transfer efficiencies. The ECOPATH $P / Q$ values are the ratios from the input parameters (Table 1). The $E E$ values (“ecotrophic efficiencies") are calculated to give a solution from eq. 7. The resultant transfer efficiencies, $E E_{p}\left(P_{p} / C_{p}\right)$, are given in the third column. When these are compared with the fractions of consumption going to trophic cannibalism, it is apparent that in two cases - jellies and benthic epifauna - there will be negative transfer efficiencies in ECOPATH. This is a consequence of the very low values for their EE required in ECOPATH. The literature values for transfer efficiency (column 5) used in this ECOTRAN example (see Steele et al, 2007) are not very different from the ECOPATH values except for planktivorous fish. Using the two different sets of assumptions, different estimates of group production are obtained (Table 2, columns 6-7). A comparison of the two sets of production estimates provides a measure of the skill of the two methods. The average difference is $53 \%$ of their mean. This is probably within the range of uncertainty of the data used to build the model and provides a rough measure of the reliability of the calculations.

\subsection{Physical fluxes in the NCC}

A model of energy flow through a shelf ecosystem must account for both new production supported by influx of nutrient-rich water and plankton production lost from the system via physical transport mechanisms. These fluxes in and out of the system are critical for coastal upwelling food webs, especially those like the NCC with a narrow continental shelf.

The major simplifying assumption used here is 2-D representation of these processes, Fig. 1. During the productive NCC upwelling season (March - September), northerly winds drive the upwelling of nutrient-rich sub-surface waters within a 10-15 km zone adjacent to the coastline 
(Huyer, 1983) and a southerly jet forms along the upwelling front (Huyer, 1983). Over most of the NCC coastline, bottom topography is simple, and the upwelling jet flows parallel to shelf bathymetry (Hickey and Banas, 2003). But in southern Oregon, complex bottom topography and prominent headlands cause the upwelling jet to separate from the coastline and cross isobaths, making this a region of focused physical export of shelf production to the deep ocean (Barth and Smith, 1998, Castelao and Barth, 2005, Keister et al., 2009). The 2-D representation of Fig. 1 is an average of these features.

As both nutrient input and physical loss rates are driven by wind stress and Ekman transport, we assume that physical loss rates from the surface mixed layer are related linearly to the rate of nitrate input to the system from deeper layers. Nutrient input rates and production loss rates are estimated from the Coastal Upwelling Index (CUI) (Schwing et al., 1996) at $45^{\circ} \mathrm{N}$, provided by the Southwest Fisheries Science Center (www.pfeg.noaa.gov). The average for the upwelling season CUI (April - September) over years 1996-2007 is used to calculate the default rates of nitrate input (value) and physical loss (value) from the shelf ecosystem.

\subsubsection{Losses of plankton from the system}

Losses of plankton groups due to fluxes out of the system in equ.(4) are defined as fractions of production $\left(L_{p}=f_{p} P_{p}\right)$. If we take $k_{p}$ as the fraction of water in the upper layer in Fig. 1 that is exported per unit time, then, for plankton in the upper layer,

$$
L_{p}=k_{p} P_{p} / r_{p} \text {; where } r_{p}=P_{p} / B_{p} \text { and is constant for each group } p
$$

We base our estimates of physical loss rates upon volume transport rates observed off southern Oregon (44.6 - 41.9 $\mathrm{N}$ ) in August 2000 (Keister et al., 2009). Over the upper $100 \mathrm{~m}$, the transport rate was approximately $1 \mathrm{~Sv}\left(8.6 \cdot 10^{10} \mathrm{~m}^{3} \mathrm{~d}^{-1}\right)$. Roughly $50 \%$ of this occurred via the upwelling jet where it was diverted seaward at Cape Blanco and 50\% was via classic Ekman cross-shelf transport. Assuming that offshore Ekman transport was similar in northern Oregon and Washington and that full upwelling strength and transport only operates half the time during the six-month upwelling season, the areal transport rate of the surface mixed layer out of the NCC model domain was estimated at $315,000 \mathrm{~km}^{2} \mathrm{y}^{-1}$, after integrating over the upper $100 \mathrm{~m}$. This twelve year average is taken as the default value for export of water from the shelf. Given biomass densities and production rates $\left(P_{p} / B_{p}\right)$ for each plankton group, the areal export rate of the surface layer, and initially ignoring vertical migration behaviors that may reduce cross-shelf transport, a rough estimate of the potential fraction of production lost from the model domain to the open ocean $\left(f_{p}=k_{p} / r_{p}\right)$ may be made (Table 3 ).

It is apparent that, for larger zooplankton, the potential physical export rate can approach the production rate (Table 3), making the populations unsustainable. It is generally accepted that diel and ontogenetic vertical migration minimize the time these populations spend in the surface Ekman layer and reduce (or reverse) offshore transport (Lamb and Peterson, 2005, Batchelder et al., 2002, Peterson, 1998); Carr et al., 2008). However, increased time at depth may also decrease recycling of $\mathrm{NH}_{4}{ }^{+}$to the euphotic zone. The resultant net flux rates are very dependent on the exact time and depth range of this migration. The detailed mechanisms for such interactive features cannot be included in a simplified annual budget, and, anyway there are inadequate data to accurately estimate these rates. For these reasons we assume that the first three plankton groups in Table 3 do not migrate, and take the loss rate, $f_{p}$, from Table 3 . For the 
larger zooplankton we take the loss rate as an unknown and introduce it as a variable, $M$, with a default value of 0.2 and range of 0.1 - 0.5. It is also likely that nitrate is taken up quickly and nitrate export losses may be ignored, but the rate of $\mathrm{NH}_{4}{ }^{+}$production should be closer to that of the zooplankton and dependant on their vertical migration. We assume that $\mathrm{NH}_{4}{ }^{+}$export varies in the same way as the larger plankton. Finally, we assume that there are no physical losses for higher trophic and benthic components and that regeneration of nutrients by these groups is ignored as they will only make very small contributions to recycling in the upper layer of this ecosystem.

There are two variables. The nutrient input varies daily and annually with the rate of coastal upwelling. We take annual nutrient input to be linearly related to the upwelling rate and use the the upwelling rate relative to the default value $(R U I)$ as a variable with mean 1.0 and range $(0.1$, 3.0). Then we vary the loss rate for the larger plankton as $M$. RUI. Study of the effects of variable upwelling on plankton has generally focused on the lower trophic components with losses regarded as closure terms. However, variable upwelling rates and vertical migration can have a marked effect on fishery yields. To show this, eq. 10 is solved for fish production under a range of nitrate input rates, and for a set of possible export rates, $M$, (Fig. 5). At low rates, fishery production increases as upwelling increases but high upwelling begins to have a detrimental effect of fishery production; and this effect is very dependent on the consequences of vertical migration by those components of the food web that contribute to fish production.

\section{$\underline{\text { 3.3 Sensitivity analysis }}$}

We conducted a simple analysis to visualize the sensitivity of the model food web to changes in the strength of each trophic link within the food web, Fig. 5. The value of each element of the predator matrix $\left(a_{c p}\right)$ was individually increased by 20\%, signifying that the energy flowing from producer $p$ to consumer $c$ was increased by 20\%. The production of prey flowing to all other predators was simultaneously reduced by a total of $20 \%$ distributed in proportion to their original values within the predator matrix. As a response index, the change in fishery production relative to production of the base model was estimated (the same could be done for each functional group). This simple analysis is the equivalent of simultaneously visualizing the effect of multiple static-model scenarios on a single functional group.

Changes that directly increase the transfer of zooplankton production to fishes increase fishery (Fig. 7). On the other hand, transfer of zooplankton production among other zooplankton groups reduces fishery production. The latter is the result of the simultaneous reduction of the direct transfer to fish groups. Overall, a 20\% redistribution of production at each node did not result in changes elsewhere in the web at levels significantly greater than $20 \%$ and most were much less.

\subsection{Trophic pathway scenarios}

A different issue concerns the relations between changes in productivity at different trophic levels. A major benefit from the bottom-up format is in the construction of scenarios to explore the consequences of changes within the lower components of the food web on production at higher trophic levels (Collie et al, 2009). By targeting specific links it is possible to amplify changes in output from the web. As an illustration, a decrease in the fraction of herbivorous 
zooplankton going to "jellies", from 0.27 to 0.03 , with a concomitant increase in food for planktivores, see Fig. 2(b), resulted in a reduction of jelly production by only 25\% but doubled planktivore fish production, Fig. 4(a). On Georges Bank a complete elimination of "carnivorous zooplankton" that included jellies, produced only a 70\% increase in planktivore production and a $50 \%$ increase for piscivores. As another example, a switch of about half of infauna production from epibenthos to benthivores, Fig. 2(b), produces quite a small change in epifauna production but a doubling in benthivore production, Fig. 4(b).

\subsection{Dynamic simulations of the NCC}

Because ECOTRAN is bottom-up, it is relatively simple to convert the steady state solution to a dynamic simulation (Steele, 2009) where the state variables are the production rates, $P_{p}$.

$$
d P_{p} / d t=r_{p}\left[e_{p} \sum_{b \neq p} a_{p b} P_{b}-\sum_{c} a_{c p} P_{p}+e_{p} G_{p}-f_{p} P_{p}\right], \quad e_{p} \leq 1 ; \quad \sum a_{c p}=1
$$

The only added data required are the growth rates of the components $(r=P / B)$ taken from ECOPATH (Ruzicka et al, 2007). The simulations are run with the MATLAB program ODE45 that uses $4^{\text {th }}$ order Runge-Kutta.

Open linear dynamic systems with independent external input are inherently stable, and are ergodic in the sense that they "forget" their initial conditions. A closed system, for example when nutrients are completely recycled, is determined by its initial conditions.

Shelf ecosystems with both external nutrient input and extensive recycling will be ergodic but the temporal response of the system to perturbation will be closely linked to the relative roles of external input and recycling. Semi-enclosed systems such as the North Sea will be dominated by recycling, whereas upwelling systems are extremely open. Here we consider the latter case for the NCC.

3.5.1 Seasonal and inter-annual variability

Annual averages have been used to demonstrate system responses, particularly at higher trophic levels (Fig. 4). However, physically driven variations at seasonal and inter-annual scales are features of most ecosystems, especially upwelling regimes such as the NCC. To illustrate the effects at different trophic levels, Coastal Upwelling Indices for 12 years (obtained from the Environmental Research Division data server, Southwest Fisheries Science Center, NOAA www.pfeg.noaa.gov/products/modeled/indices) are used to determine variable daily flux rates (Fig. 6). The initial conditions for the simulation were the values obtained using the 12-year average flux rate. The CUI shows considerable inter-annual as well as seasonal variation. But the differences in production rates between years (Fig. 6) especially in maximum values, are much less, due to the limiting effects at high flushing rates (Fig. 4). However, this same limiting effect means that the annual average of the daily rates for fish production is significantly less than obtained using the annual average flux rate (Fig. 4).

\section{$\underline{\text { 3.5.2 Non-linear responses }}$}


A major constraint on this kind of model is the strict bottom-up transfer of energy and information, compared with a system with non-linear prey-predator interactions. It is simple to extend this model to incorporate non-linear functional relations between predators and prey. As one example we replace the $a_{c p} P_{p}$ terms in eq. 11 with

$$
\left(1+m_{p}\right) a_{c p} P_{p} P_{c} /\left(m_{p} S_{c}+P_{c}\right)
$$

where $S_{p}$ is the linear steady state solution for $P_{p} . S_{p}$ are used as the initial conditions. Then taking the $m_{p}>0$ gives a range of non-linear conditions. This functional form involving predator control can be regarded as a simplification of Beddington-DeAngelis functional response (Skalski and Gilliam, 2001) and is similar to the basic form used in ECOSIM (Steele, 2009). Fig. 7 shows the response with $m_{p}=1$ for all $p$. This corresponds to the "ECOSIM" default condition (the "vulnerability" parameter, $V=1$ ). There are changes in most of the variables with some increasing in amplitude (e.g. producers) and others decreasing (e.g. herbivorous zooplankton). But the most significant difference is that, over 12 years, benthivores and piscivores do not reach equilibrium. This decreased resilience is expected (Steele, 2009). Given the lack of information on the actual prey-predator interactions, are such non-linear representations of functional groups any more "realistic" than the linear condition (Steele, 1974)? It may be better to regard the nonlinear outputs as indicators of potential instabilities in the model rather than in the ecosystem.

\section{Discussion}

There is considerable interest in methods for the assembly of end-to-end models as a means to understand the effects of climate and fisheries on marine ecosystems. We demonstrate methods to construct E2E models that can make use of the large number of data sets available as inputs to ECOPATH. The transition to a bottom-up format allows relatively easy integration with simplified descriptions of microbial food webs, although there are a number of detailed technical considerations such as trophic cannibalism and the selection of independent variables, that need to be resolved.

Since topographic variability is a defining feature of shelf ecosystems, it is essential to include this in end-to-end representations, especially when one aim is the comparison of such systems (Murawski et al, 2009). For large semi-enclosed systems such as the North Sea, input/output fluxes may be less significant than for smaller offshore regions such as Georges Bank; and recycling rates more important. Overall, varying flux rates can be expected to be a defining feature in the comparison of shelf ecosystems.

A contentious aspect concerns how much spatial and temporal detail is required for an appropriate balance. The choice among different models with a range of complexity depends on the intended uses. Comparisons of diverse ecosystems excludes approaches that are not easily generalized (ERSEM, Baretta et al, 1995; ATLANTIS, Fulton and Smith, 2004). The application here of relatively simple descriptions of the physics, the microbial processes and the upper trophic levels is intended to provide a model of intermediate complexity (Hannah et al, 2009) since a major aim is to develop comparable descriptions of a range of shelf ecosystems (Murawski et al, 2009). 
Correspondingly there is considerable variability in the amount and type of detail introduced into the upper food web. Many recent models avoid introduction of benthic food webs (Rose et al., 2010). ECOPATH (Christensen and Pauly, 1993) is an exception since it contains benthic functional groups. But ECOPATH does not include physical processes driving a microbial food web. The significance of benthic recycling for both production rates and resilience of fish communities will depend on the residence time of water within the shelf system. The connection between nutrient recycling rates and physical residence time scales is a critical factor in the comparison of food webs.

The linear approach used here and in ECOPATH allows both steady state and dynamic analyses. Models with integral non-linear predator-prey interactions may introduce more realism but also much more complexity since solutions can only be obtained by dynamic simulation. The linear steady state solutions of ECOPATH and ECOTRAN can be used as initial conditions for non-linear dynamic simulations in ECOSIM or as illustrated in Fig. 7. The main issue concerns the validity of the large number of poorly defined parameters required (Plaganyi and Butterworth, 2004; Rochet and Rice, 2009). There can be similar concerns for spatially structured fish stock assessments (Holland et al., 2010)

For both the physical and the ecosystem components, another concern is the sensitivity of the results to uncertainty both in functional form and in parameter values; as a general problem (Yodzis, 1988), and for ECOPATH (Essington, 2007). From the sensitivity analysis, Fig. 5, changes in the general output may be comparable to inputs. But scenario calculations (Fig. 4), show that small targeted changes in the prey-predator matrix can be amplified in the production rates at higher trophic levels giving the impression of non-linear responses. More work on methods for skill assessment is required.

The ECOTRAN program is designed to display the consequences of changes in physical forcing and in the internal structure of the food web, on productivity of the upper trophic levels, especially fish. The steady state solutions depend on a linear matrix approximation, but the effects of variable nutrient input are non-linear, Fig. 3, since the upwelling rates affect both production and retention. Also the transfer of production by predation is "bottom-up", but the recycling of nutrients is "top-down". So the control processes are mixed, Table 4. These factors are apparent in the output from the application to the Northern California Current (NCC) ecosystem.

Usually, the problems of retention of plankton in upwelling systems are regarded as part of the closure conditions on NPZD models (Lamb and Peterson, 2005, Batchelder et al., 2002, Peterson, 1998; Carr et al., 2008). We show here that this relatively unknown factor will affect significantly the fish production. Variable upwelling rates and behavioral changes in vertical migration can have a marked effect on fishery yields. These relations emphasize the importance of including physical forcing and lower trophic responses in food web models intended for ecosystem-based management of fish stocks.

In general, the sensitivity of changes in fish production to changes in the internal structure of the food web is expected to be proportionate, particularly when the changes in one link are re- 
distributed over several other links, Fig. 4. When fluxes are transferred to higher trophic levels, Fig. 4, small changes in production at a lower level can produce significant increases in productivity of fish guilds. These large changes in upper level productivity are reminiscent of regime shifts that arise in non-linear models of ecologically simple systems (Scheffer et al., 2001), where small perturbations can induce large effects. The results here show that non-linear functional relations are not necessary to induce amplifications. They can be produced by moderately complicated food web structure. 


\section{References}

Aydin, K.Y., McFarlane, G.A., King, J.R., Megrey, B.A. and Myers, K.W. (2005) Linking oceanic food webs to coastal production and growth rates of Pacific salmon (Oncorhynchus spp.), using models on three scales. Deep Sea Res. (II Top. Stud. Oceanogr.), 52, 757-780.

Baretta, J.W., Ebenhoh, W. and Ruardij, P. 1995. The European Regional Seas, Ecosystem Model, a complex ecosystem model. Netherlands J. of Sea Res. 33: 233-246.

Barth, J.A. and Smith, R.L. (1998) Separation of a coastal upwelling jet at Cape Blanco, Oregon, USA. S. Afr. J. Mar. Sci., 19.

Batchelder, H.P., Edwards, C.A. and Powell, T.M. (2002) Individual-based models of copepod populations in coastal upwelling regions: implications of physiologically and environmentally influenced diel vertical migration on demographic success and nearshore retention. Prog. Oceanogr., 53, 307-333.

Carr, D.S., Capet, X.J., McWilliams, J.C., Pennington, J.T. and Chavez, F.P. 2008. The influence of diel vertical migration on zooplankton transport and recruitment in an upwelling region: estimates from a coupled behavioral-physical model. Fish. Oceanogr. 17:1-15.

Castelao, R.M. and Barth, J.A. (2005) Coastal ocean response to summer upwelling favorable winds in a region of alongshore bottom topography variations off Oregon. J. Geophys. Res., 110, doi:10.1029/2004JC002409.

Christensen, V. and Walters, C.J. (2004) Ecopath with Ecosim: methods, capabilities and limitations. Ecol. Model., 172, 109-139.

Christensen, V., Pauly, D. (Eds.), 1993. Trophic models of aquatic ecosystems.The International Center for Living Aquatic Resources Management (ICLARM) Conference Proceedings, vol. 26. ICLARM, Manila, Philippines

Collie, J.S., Gifford, D.J. and Steele, J.H. 2009. End-to-end foodweb control of fish production on Georges Bank. ICES Journal of Marine Science. 66:2223-2232.

Eppley, R.W. and Peterson, B.J. 1979. "Particulate organic matter flux and planktonic new production in the deep ocean". Nature 282: 677-680.

Essington, T.E. 2007. Evaluating the sensitivity of a trophic mass-balance model (ECOPATH) to imprecise data inputs. Can. j. Fish. Aquat. Sci. 64: 628-637.

Fulton, E. A., and Smith, A. D. M. (2004). Lessons learnt from a comparison of three ecosystem models for Port Phillip Bay, Australia. African Journal of Marine Science, 26: 219-243.

Hales, B., Karp-Boss, L., Perlin, A. and Wheeler, P.A. (2006) Oxygen production and carbon sequestration in an upwelling coastal margin. Global Biogeochem. Cycles, 20, doi:10.1029/2005GB002517.

Hannah, C., Vezina, A. and St John, M. 2009. The case for marine ecosystem models of intermediate complexity. Prog. in Oceanogr. 84:121-128.

Hickey, B.M. and Banas, N.S. (2003) Oceanography of the U.S. Pacific Northwest coastal ocean and estuaries with application to coastal ecology. Estuaries, 26, 1010-1031. 
Holland, D. and Herrera, G. 2010. Benefits and risks of increased spatial resolution in the management of fishery metapopulations under uncertainty. Nat. Resource Modeling. 23:494-519.

Huyer, A. (1983) Coastal upwelling in the California Curent. Prog. Oceanogr., 12, 259-284.

Keister, J.E., Peterson, W.T. and Pierce, S.D. (2009) Zooplankton distribution and cross-shelf transfer of carbon in an area of complex mesoscale circulation in the northern California Current. Deep-Sea Research I, 56, 212-231.

Lamb, J. and Peterson, W.T. (2005) Ecological zonation of zooplankton in the COAST study region off Central Oregon in June and August 2001 with consideration of retention mechanisms. J. Geophys. Res. (C Oceans), 110, [np].

Moloney, C., St John, M., Denman, K., Karl, D., Koster, F. Sundby, S andWilson, R. (2010) Weaving marine food webs from end to end under global change. J. Ma. Sys., 84, 212-229.

Murawski, S., Steele, J., Taylor, P., Fogarty, M., Sissenwine, M., Ford, M., Suchman C. 2010. Why compare marine ecosystems? ICES Journal Marine Science; 67, 1-9.

Peterson, W. (1998) Life cycle strategies of copepods in coastal upwelling zones. J. Mar. Syst., 15, 313-326.

Petihakis, G., C. J. Smith, G. Triantafyllou, G. Sourlantzis, K-N. Papadopoulou, . Pollani and G. Korres 2007 Scenario testing of fisheries management strategies using a high resolution ERSEM-POM ecosystem model. ICES Journal of Marine Science: 64(9):1627-1640

Plaganyi, E.E., Butterworth, D.S., 2004. A critical look at the potential of ECOSIM with ECOPATH to assist in practical fisheries management. African Journal Marine Science, 26, 261-287.

Rochet, M-J and Rice, J.C. 2009. Simulation-based management strategy evaluation: ignorance disguised as mathematics. ICES J. Mar. Sci., 66: 754-762.

Rose, K.A. (and 25 others). 2010. End-to-end models for the analysis of marine ecosystems: challenges, issues and next steps. Marine and Coastal Fisheries, 2: 115-130.

Ruardij, P. and Raaphorst, W. 1995. Benthic nutrient regeneration in the ERSEM ecosystem model of the North Sea. Netherlads J.sea Res. 33: 453-483.

Ruzicka, J.J., Brodeur, R.D. and Wainwright, T.C. (2007) Seasonal food web models for the Oregon inner-shelf ecosystem: investigating the role of large jellyfish. CalCOFI Reports, 48, 106-128.

Scheffer et al, 2001. Catastrophic shifts in ecosystems. Nature, 413:591-596

Schwing, F.B., O’Farrell, M., Steger, J.M. and Baltz, K. (1996) Coastal upwelling indices wet coast of North America 1946-95. SWFSC, NOAA-TM-NMFS-SWFSC-231. 32pp.

Seitzinger, S., and Giblin, A. 1996. Estimating denitrification in North Atlantic continental shelf sediments. Biogeochemistry. 35: 235-260.

Simpson, H.J., Hunter, J.R. (1974). Fronts in the Irish Sea. Nature, 1250, 404-406. 
Sissenwine, M.P., Cohen, E.B., Grosslein, M.D. (1984). Structure of the Georges Bank ecosystem. Rapports et procès-verbaux des réunions / Commission internationale pour l'exploration scientifique de la Mer, 183:243-254

Skalski, G.T. and Gilliam, J.F. 2001. Functional responses with predator interference: viable alternatives to the Holling II model. Ecology, 82: 3083-3092

Steele, J.H. 1974. The structure of marine ecosystems. Harvard University Press. Cambridge, Mass. 128 p.

Steele, J.H. 2009. Assessment of some linear food web methods. Journal of Marine Systems, 76: 186-194.

Steele, J., Collie, J., Bisagni, J., Fogarty, M., Gifford, D., Link, J., Sieracki, M., Sullivan, B., Beet, A., Mountain, D., Durbin, E., Palka, D. and Stockhausen, W. (2007) Balancing endto-end budgets of the Georges Bank ecosystem. Prog. Oceanogr., 74, 423-448.

Travers, M., Shin, Y., Jenning, S. and Cury, P. (2007) towards end-to-end models for investigating the effects of climate and fishing in marine ecosystems.Prog. Oceanogr. 75, 751-770.

Walters, C., Christensen, V. and Pauly, D. (1997) Structuring dynamic models of exploited ecosystems from trophic mass-balance assessments. Rev. Fish Biol. Fish., 7, 139-172.

Yodzis, P. 1988. The indeterminacy of ecological interactions as perceived through perturbation experiments. Ecology, 69: 508-515. 


\section{Figure Captions}

Fig. 1. Schematic of lower trophic level processes involved in shelf ecosystems

Fig. 2. (A) The transpose of the NCC ECOPATH food web, from top down to bottom up, showing the ECOPATH outputs - Phytoplankton and Detritus (pelagic and benthic) - as inputs. The purple line indicates recycling.

(B)The revised web with nutrient input and recycling (dashed red) added. The detrital components are supplied by fecal material (solid red) from the zooplankton and benthic infauna. The thickness of the lines is an approximate index of magnitude of the links.

Fig. 3. Effect on fish production available to commercial fisheries of variable upwelling as measured by the Coastal Upwelling Index, and of a range of horizontal loss rates for the larger zooplankton and recycled nutrients.

Fig. 4. The effects of alterations in the food web (a) diverting some of herbivore plankton production from jellies to planktivores, (b) diverting some infauna production from epifauna to benthivores

Figure 5. Sensitivity analysis of fisheries production to a $20 \%$ increase in the strength of individual trophic linkages. Producer groups are arrayed across the top and consumer groups along the side. Dot size is proportional to the change in fishery production. Green represents increased production. Red represents decreased production. Gray dots represent non-existent linkages

Figure 6. Seasonal and inter-annual variations in upwelling index and the effects on producers, intermediate and higher trophic levels

Figure 7. Effects on various trophic components of introducing non-linearity into the dynamic simulations, using the default form in ECOSIM (see text). 
Table 1. Distribution of the products of consumption by zooplankters

$\begin{array}{lllll} & \text { Micro } & \text { Herbiv } & \text { Carniv } & \text { Jellies } \\ & & & & \\ \text { Percentage for growth } & 30 & 30 & 20 & 20 \\ \text { Percentage for feces } & 35 & 35 & 40 & 40 \\ \text { Destination of feces } & \text { pelagic } & \text { benthic } & \text { benthic } & \text { benthic } \\ \text { Percent } \mathrm{NH}_{4}^{+} \text {above euphotic zone } & 35 & 17.5 & 20 & 20 \\ \text { Percent } \mathrm{NH}_{4}^{+} \text {below euphotic zone } & 0 & 17.5 & 20 & 20\end{array}$


Table 2. Comparisons of the methods to estimate production of the main trophic components used by ECOPATH and ECOTRAN (see text for details)

\begin{tabular}{lrrrrrrr} 
& $\begin{array}{r}\text { ECOPATH } \\
\text { P/Q }\end{array}$ & EE & ECOPATH Trophic & ECOTRAN & \multicolumn{2}{c}{ Production } \\
& & & Tr. Eff & Cannib. & Tr. Eff. & ECOTR & ECOP \\
micro-zooplankton & 0.35 & 0.8088 & 0.2831 & 0 & 0.3 & 1.8705 & 1.8005 \\
herbiv-zooplankton & 0.25 & 0.5399 & 0.135 & 0.0339 & 0.3 & 2.3394 & 0.8931 \\
carniv-zooplankton & 0.25 & 0.7045 & 0.1761 & 0.0553 & 0.2 & 0.3097 & 0.0724 \\
jellies & 0.25 & 0.0662 & 0.0166 & 0.1123 & 0.2 & 0.7054 & 0.2404 \\
cephalopods & 0.3 & 0.8866 & 0.266 & 0.005 & 0.2 & 0.0038 & 0.006 \\
planktivorous fish & 0.25 & 0.9832 & 0.2458 & 0.0124 & 0.1 & 0.0166 & 0.0394 \\
piscivorous fish & 0.0828 & 0.706 & 0.0584 & 0.0138 & 0.1 & 0.0068 & 0.0067 \\
benthic fish & 0.1102 & 0.6668 & 0.0735 & 0.0442 & 0.1 & 0.0031 & 0.0065 \\
benthic infauna & 0.2 & 0.7841 & 0.1568 & 0 & 0.2 & 0.1741 & 0.3523 \\
epifauna & 0.2 & 0.2365 & 0.0473 & 0.1431 & 0.2 & 0.026 & 0.163 \\
seabirds & 0.0008 & 0 & 0 & 0.0001 & 0.05 & 0.0001 & 0 \\
marine mammals & 0.0048 & 0 & 0 & 0 & 0.05 & 0.0001 & 0
\end{tabular}


Table 3. Potential fraction of production transported out of NCC model domain $\left(f_{p}\right)$ in the absence of behavioral retention mechanisms:

\begin{tabular}{|c|c|c|c|c|c|}
\hline & $\begin{array}{c}B \\
\mathrm{t} \mathrm{km}^{-2}\end{array}$ & $\begin{array}{l}P / B \\
\mathrm{y}^{-1}\end{array}$ & $\begin{array}{l}\text { production } \\
\text { rate } \\
\mathrm{t} \mathrm{km}^{-2} \mathrm{y}^{-1} \\
\end{array}$ & $\begin{array}{l}\text { export } \\
\text { rate } \\
\mathrm{t} \mathrm{km}^{-2} \mathrm{y}^{-1} \\
\end{array}$ & $\begin{array}{l}\text { fraction of production } \\
\text { exported from domain } \\
\qquad f_{p}\end{array}$ \\
\hline producers & 67.4 & 141.74 & 9549.0 & 397.0 & 0.04 \\
\hline $\begin{array}{r}\text { micro- } \\
\text { zooplankton }\end{array}$ & 64.6 & 36.50 & 2358.0 & 380.7 & 0.16 \\
\hline $\begin{array}{l}\text { herbivorous- } \\
\text { zooplankton }\end{array}$ & 33.4 & 37.04 & 1235.9 & 196.6 & 0.16 \\
\hline $\begin{array}{l}\text { carnivorous- } \\
\text { zooplankton }\end{array}$ & 15.6 & 7.72 & 120.7 & 92.2 & 0.76 \\
\hline $\begin{array}{l}\text { gelatinous- } \\
\text { zooplankton }\end{array}$ & 25.7 & 15.00 & 385.5 & 151.5 & 0.39 \\
\hline euphausiids & 27.0 & 6.11 & 165.0 & 159.1 & 0.96 \\
\hline
\end{tabular}


Table 4. The production matrix for the NCC ecosystem expressed as percentages of nitrogen or carbon transferred from food web producer $p$ (columns) to consumer $c$ (rows) including recycling in the lower web. Note that in the calculations the $a_{c p}$ are proportions. (see text for details)

\section{$\begin{array}{llllllllllllllllll}1 & 2 & 3 & 4 & 5 & 6 & 7 & 8 & 9 & 10 & 11 & 12 & 13 & 14 & 15 & 16 & 17 & 18\end{array}$}

$0,0,70,0,35,18,21,46,0,0,0,0,0,0,0,0,0,0 ; 1$ nutrients $100,0,0,0,0,0,0,0,0,0,0,0,0,0,0,0,0,0 ; 2$ producers

$0,0,0,0,35,0,23,0,0,0,0,0,0,0,0,0,0,0 ; 3$ pelagic detritus $0,0,0,0,0,37,43,23,0,0,0,0,0,0,0,0,0,0 ; 4$ benthic detritus

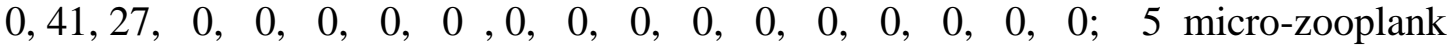
$0,46, \quad 0, \quad 3,25, \quad 0, \quad 0, \quad 0, \quad 0,0,0, \quad 0,0, \quad 0,0, \quad 0, \quad 0, \quad 0 ; \quad 6$ herb-zooplank $0,2,0,0,1,8,0,4,0,0,0,0,0,8,0,0,0,0 ; 7$ carn-zooplank $0,10,3,0,4,9,4,0,0,0,0, \quad 0,0,0,0,0,0,0 ; \quad 8$ jellies $0,0, \quad 0,0,0,1,1,0,0,12,0,0,0,4,0,0,0,0 ; 9$ cephalopods $0,1,0, \quad 0,0, \quad 5, \quad 6, \quad 3,2,0,0,0,0,2,0,0,0,0 ; 10$ planktiv fish $0,0,0,0,0,2,1,1,66,60,0,84,0,25,0,0,0,0 ; 11$ piscivor fish $0,0,0,0,0,1,1,1,22,13,18,0,5,57,0,0,0,0 ; 12$ benthic fish $0,0,0,76,0,0,0,0,0,0,0,0,0,0,0,0,0,0 ; 13$ infauna $0, \quad 0, \quad 0,22,0,1,2,0,2,4,1,6,95,0,0,0,0,0 ; 14$ epifauna $0, \quad 0, \quad 0, \quad 0, \quad 0, \quad 0, \quad 0, \quad 0, \quad 6, \quad 9, \quad 0, \quad 0, \quad 0,0,0,0,0, \quad 0 ; 15$ seabirds $0,0, \quad 0, \quad 0, \quad 0, \quad 0, \quad 0, \quad 0,3, \quad 1,5, \quad 5,0,3,0,0,0,0 ; 16$ mar mammals $0, \quad 0, \quad 0, \quad 0,0, \quad 0,0,0,0,1,76,5,0,1,0,0,0,0 ; 17$ fisheries $0,0, \quad 0,0, \quad 0, \quad 0, \quad 0, \quad 0,0,0, \quad 0,0, \quad 0,0,100,100,100,0 ; 18$ harvest 


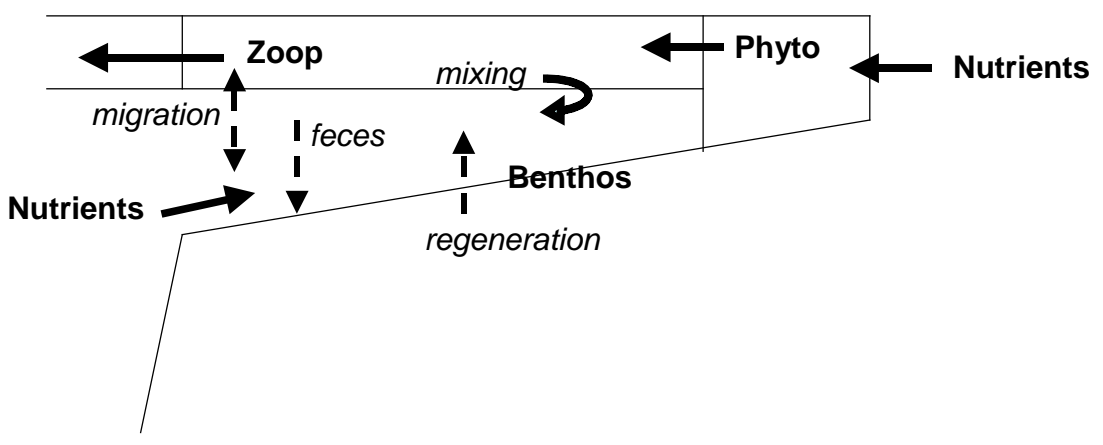

Fig. 1. Schematic of lower trophic level processes involved in shelf ecosystems 

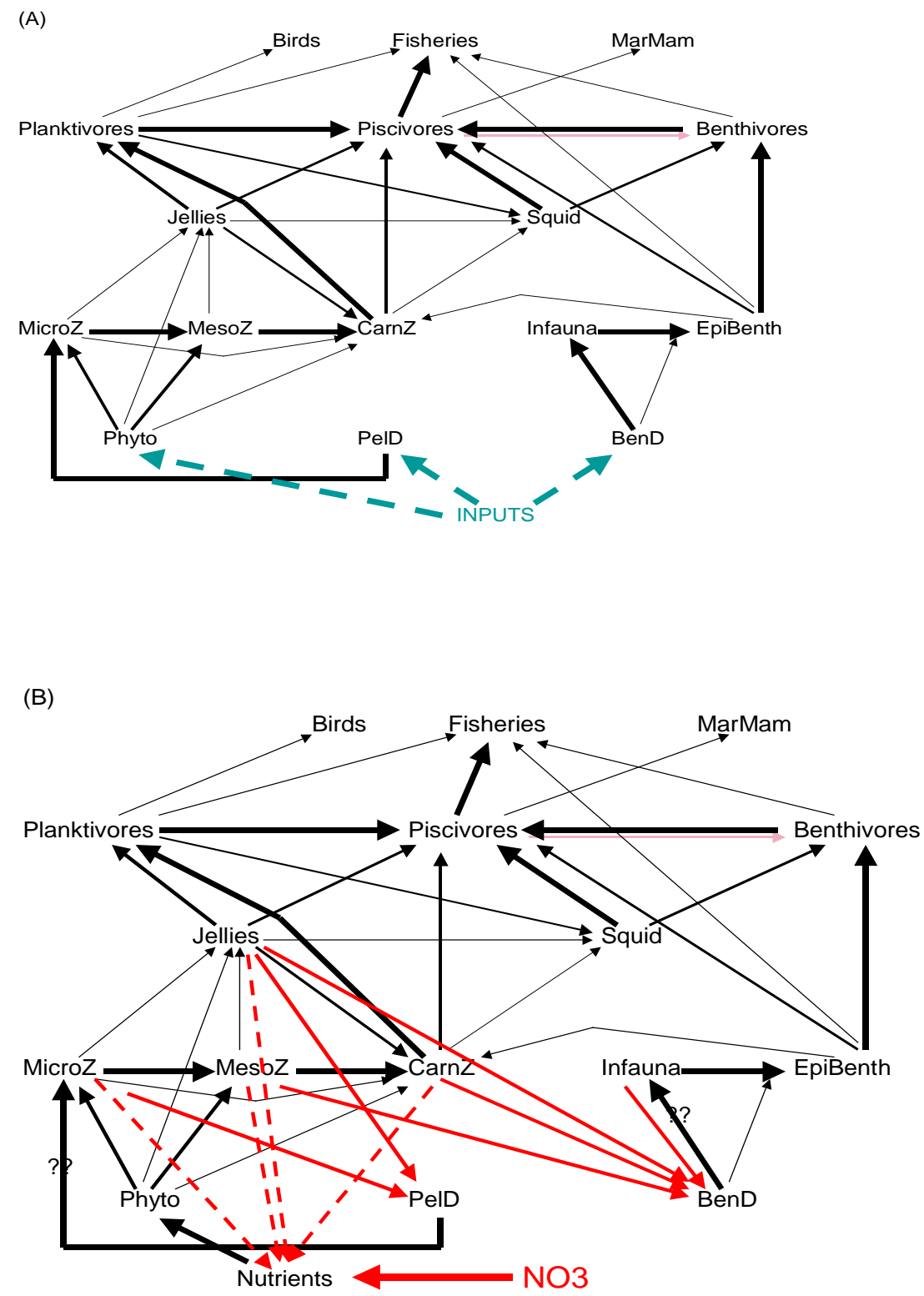

Fig. 2. (A) The transpose of the NCC ECOPATH food web, from top down to bottom up, showing the ECOPATH outputs - Phytoplankton and Detritus (pelagic and benthic) - as inputs. The purple line indicates recycling.

(B)The revised web with nutrient input and recycling (dashed red) added. The detrital components are supplied by fecal material (solid red) from the zooplankton and benthic infauna. The thickness of the lines is an approximate index of magnitude of the links. 


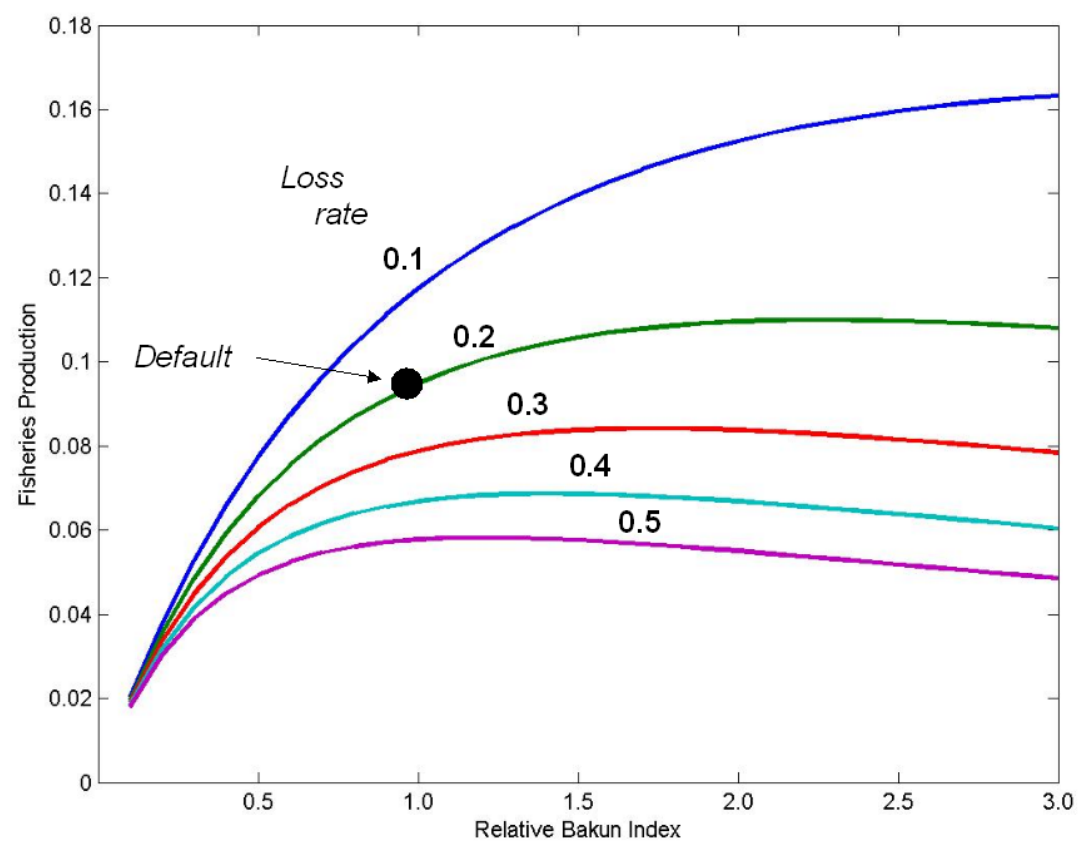

Fig. 3. Effect on fish production available to commercial fisheries of variable upwelling as measured by the Coastal Upwelling Index, and of a range of horizontal loss rates for the larger zooplankton and recycled nutrients. 

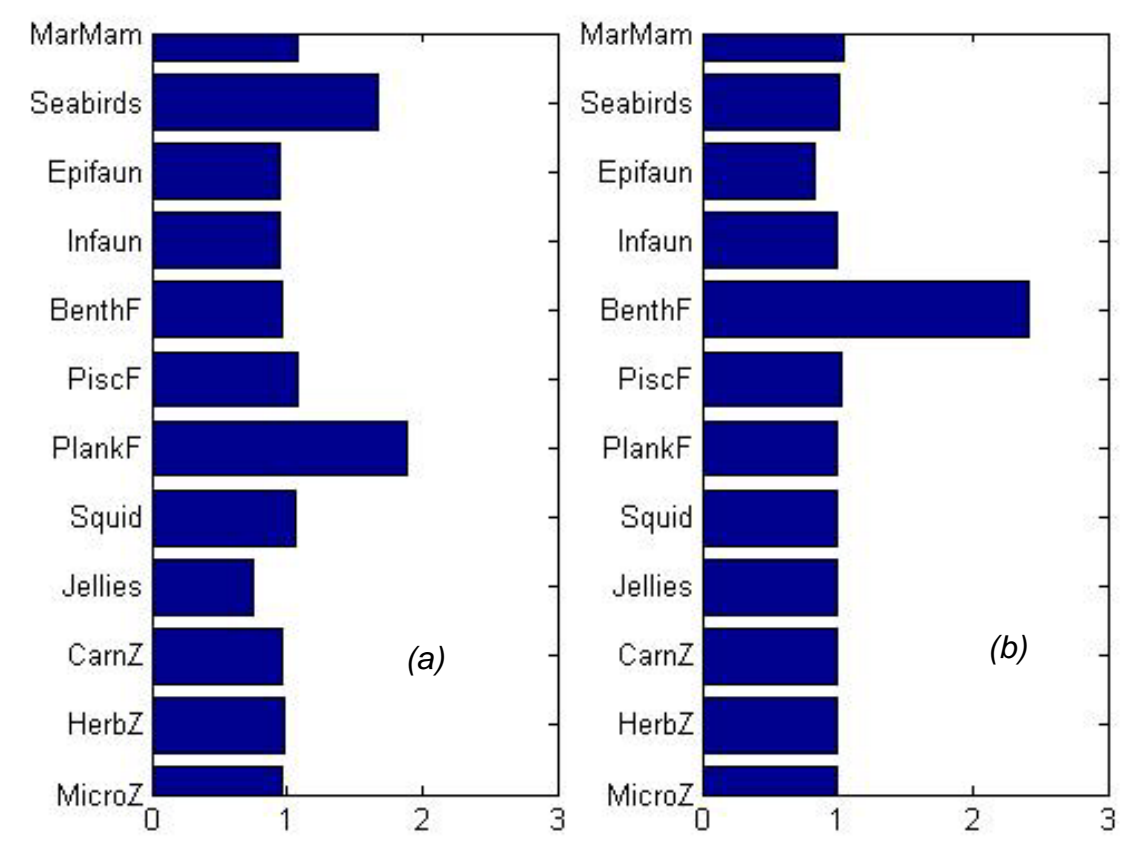

Fig. 4. The effects of alterations in the food web (a) diverting some of herbivore plankton production from jellies to planktivores, (b) diverting some infauna production from epifauna to benthivores. 
Figure 5. Sensitivity analysis of fisheries production to a $20 \%$ increase in the strength of individual trophic linkages. Producer groups are arrayed across the top and consumer groups along the side. Dot size is proportional to the change in fishery production. Green represents increased production. Red represents decreased production. Gray dots represent non-existent linkages 

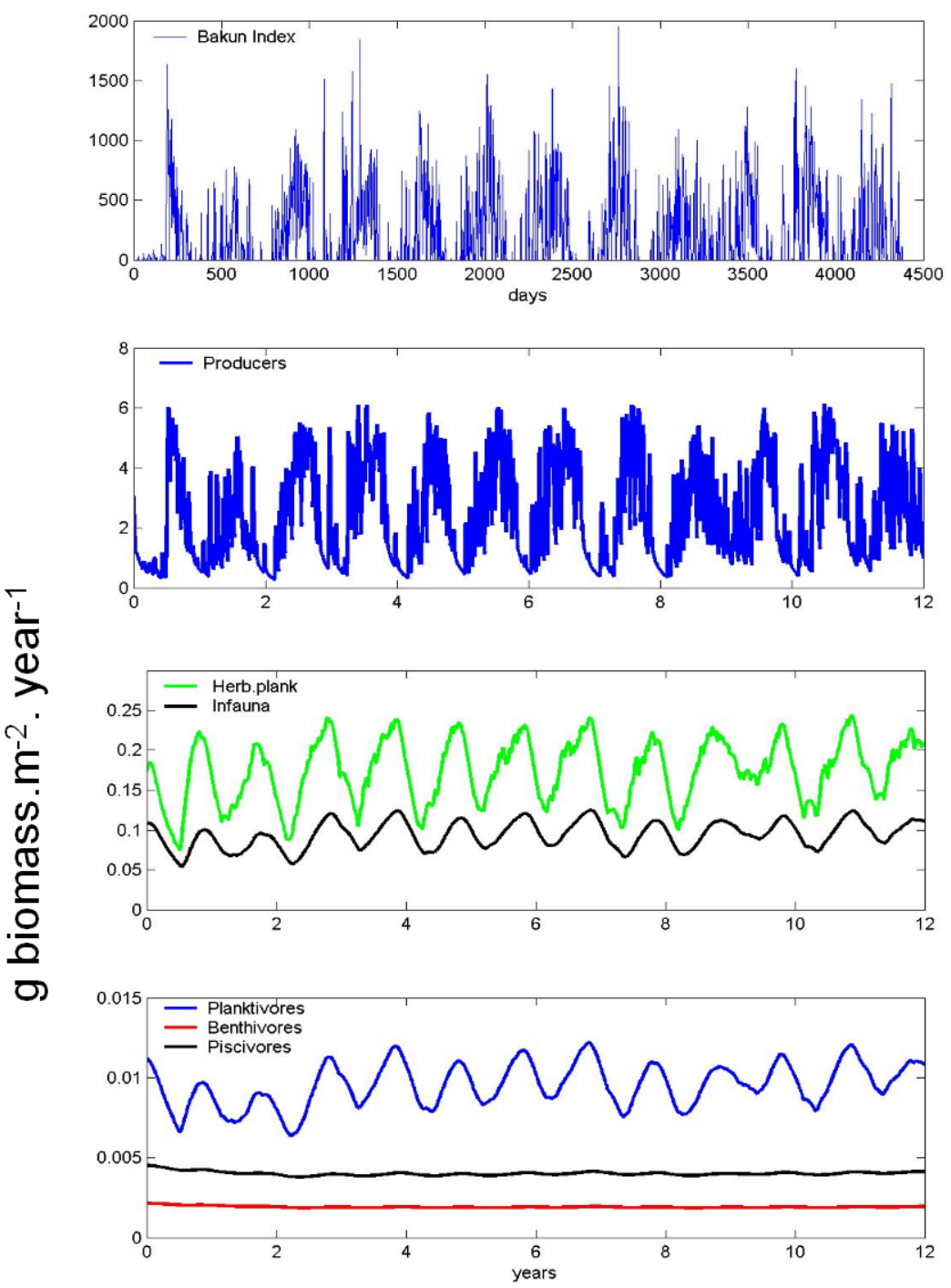

Figure 6. Seasonal and inter-annual variations in upwelling index and the effects on producers, intermediate and higher trophic levels 


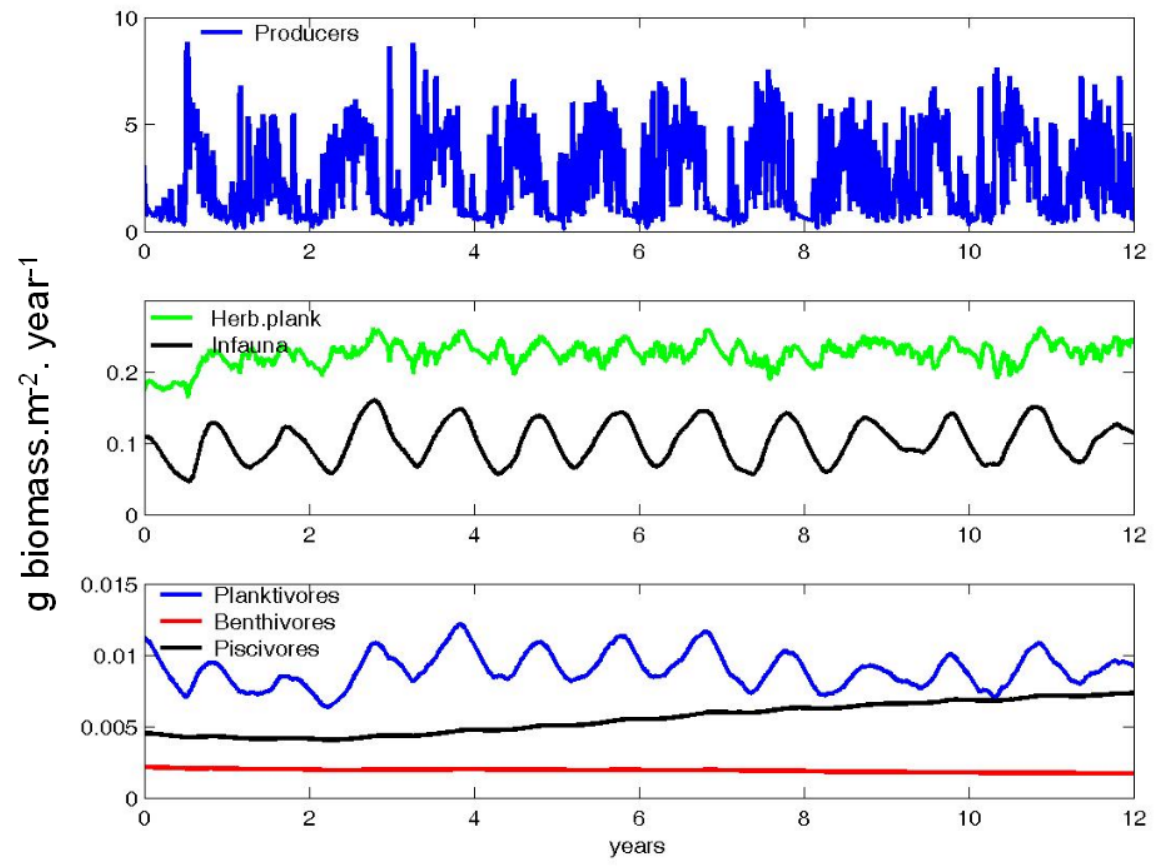

Figure 7. Effects on various trophic components of introducing non-linearity into the dynamic simulations, using the default form in ECOSIM (see text). 